\title{
Primary hyperparathyroidism: are we doing a good job?
}

\author{
Rafael Pérez-Soto, Miguel F. Herrera \\ Department of Surgery, National Institute for Medical Sciences and Nutrition Salvador Zubirán, Mexico City, Mexico \\ Correspondence to: Miguel F. Herrera, MD, PhD. Department of Surgery, National Institute for Medical Sciences and Nutrition Salvador Zubirán, \\ Mexico City, Mexico. Email: miguelfherrera@gmail.com. \\ Provenance: This is an invited article commissioned by the Section Editor Xiao-Li Liu (Deputy Director of Science and Education Department, \\ Department of Thyroid Surgery, China-Japan Union Hospital of Jilin University, Changchun, China). \\ Comment on: Kuo EJ, Al-Alusi MA, Du L, et al. Surgery for Primary Hyperparathyroidism: Adherence to Consensus Guidelines in an Academic \\ Health System. Ann Surg 2019;269:158-62.
}

Submitted Jun 17, 2019. Accepted for publication Jul 12, 2019.

doi: $10.21037 /$ gs.2019.07.06

View this article at: http://dx.doi.org/10.21037/gs.2019.07.06

We recently read with high interest the publication by Kuo et al. (1) entitled "Surgery for primary hyperparathyroidism: adherence to consensus guidelines in an academic health system". In the publication the authors have clearly addressed a problem that has been identified since the first consensus guidelines for the management of primary hyperparathyroidism were published (2). It seems that the main issue that explains the low adherence reported by the authors is a cumulative sequence of inappropriate clinical decisions by primary care physicians, endocrinologists and surgeons as shown by the Sankey diagram and data. Some aspects related with clinical decisions for surgical referrals and/or treatment not addressed in the guidelines might influence the low adherence ratio. These include patient's treatment preference, difficult medical follow-up, advanced age, comorbidities and other socioeconomics factors.

Considering that the lack of knowledge in the evaluation and management of primary hyperparathyroidism by clinicians plays and important role in the problem, we should ask ourselves. Are we endocrine surgeons failing as educators? An important role as endocrine surgeons is medical education in the field, and the development of guidelines does not seem to be enough. Mechanisms to disseminate the scientific literature that support the management of primary hyperparathyroidism are undoubtedly needed.

In spite of these, guidelines for the management of patients with asymptomatic primary hyperparathyroidism will need to address in the near future with greater depth in the natural course of patients with mild hypercalcemic or normocalcemic hyperparathyroidism. Benefits of surgical treatment in elderly patients will need to be emphasized. Studies in old patients have shown to be safe irrespective of comorbidities with significant improvement in symptoms $(3,4)$. Progress in minimally invasive techniques and adjuvants for parathyroidectomy such as intraoperative parathyroid hormone determinations, has significantly impacted cure rate avoiding surgical reinterventions and may increase the confidence to refer patients for surgical treatment.

\section{Acknowledgments}

None.

\section{Footnote}

Conflicts of Interest: The authors have no conflicts of interest to declare.

Ethical Statement: The authors are accountable for all aspects of the work in ensuring that questions related to the accuracy or integrity of any part of the work are appropriately investigated and resolved.

\section{References}

1. Kuo EJ, Al-Alusi MA, Du L, et al. Surgery for Primary Hyperparathyroidism: Adherence to Consensus Guidelines in an Academic Health System. Ann Surg 2019;269:158-62. 
2. Sosa JA, Powe NR, Levine MA, et al. Profile of a clinical practice: Thresholds for surgery and surgical outcomes for patients with primary hyperparathyroidism: a national survey of endocrine surgeons. J Clin Endocrinol Metab 1998;83:2658-65.

3. Wu B, Haigh PI, Hwang R, et al. Underutilization of parathyroidectomy in elderly patients with primary

Cite this article as: Pérez-Soto R, Herrera MF. Primary hyperparathyroidism: are we doing a good job? Gland Surg 2019;8(5):581-582. doi: 10.21037/gs.2019.07.06 hyperparathyroidism. J Clin Endocrinol Metab 2010;95:4324-30.

4. Stechman MJ, Weisters M, Gleeson FV, et al. Parathyroidectomy is safe and improves symptoms in elderly patients with primary hyperparathyroidism (PHPT). Clin Endocrinol (Oxf) 2009;71:787-91. 